\title{
An Iridium-based Catalyst System for Metathesis/lsomerization of Acyclic Olefins, including Methyl Oleate
}

\author{
Marcia B. France, a Jerald Feldman*b and Robert H. Grubbs*a \\ a The Arnold and Mabel Beckman Laboratory of Chemical Synthesis, Division of Chemistry and Chemical \\ Engineering, California Institute of Technology, Pasadena, California 91125, USAT \\ b Central Research and Development, E. I. du Pont de Nemours \& Company Inc., Wilmington, Delaware, $19880-$ \\ 0328, USA
}

Reaction between $\left[\mathrm{Ir}(\mathrm{coe})_{2} \mathrm{Cl}\right]_{2}$ (coe $=$ cyclooctene) and $\mathrm{AgO}_{2} \mathrm{CCF}_{3}$ (4 equiv.) produces a highly active system for metathesis/isomerization of acyclic olefins, including methyl oleate.

Olefin metathesis catalysts based on group 8-10 metals display tremendous tolerance of functional groups as compared to catalysts based on early metals: ruthenium, osmium and iridium catalysts are known that can metathesize olefins in the presence of esters, alcohols, ketones and even Brönsted acids. ${ }^{1}$ However, the activity of these catalysts is almost invariably limited to ring-opening metathesis polymerization

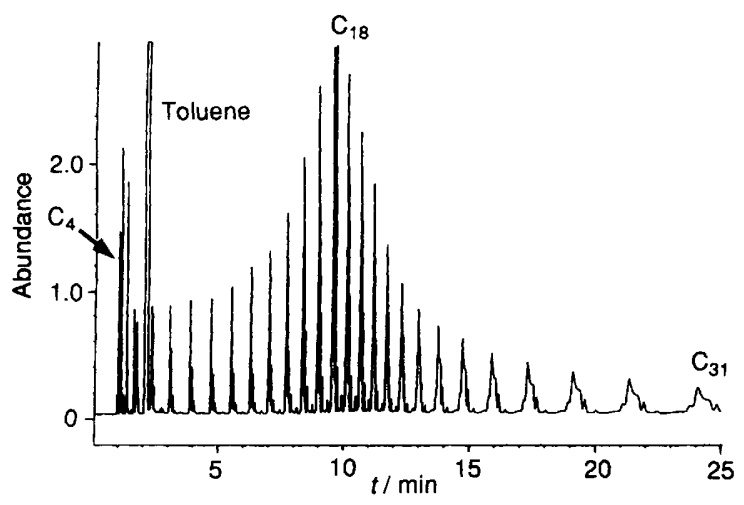

Fig. 1 Gas chromatogram of the product mixture formed in Scheme 1; for clarity, only the peaks corresponding to $\mathrm{C}_{4}, \mathrm{C}_{18}$ and $\mathrm{C}_{31}$ olefins are labelled. $\mathrm{C}_{18}$ olefins account for $c a .10 \%$ of the olefins present

$$
\text { Octadec-1-ene } \stackrel{\mathfrak{i}}{\rightarrow} \mathrm{C}_{4}, \mathrm{C}_{5}, \mathrm{C}_{6}, \ldots \mathrm{C}_{31} \text { olefins }
$$

Scheme 1 Reagents and conditions: $\mathrm{i},\left[\mathrm{Ir}(\mathrm{coe})_{2} \mathrm{Cl}\right]_{2} \quad(4 \mathrm{~mol} \%)$, $\mathrm{AgO}_{2} \mathrm{CCF}_{3}(16 \mathrm{~mol} \%)$, toluene, $25^{\circ} \mathrm{C}, 9 \mathrm{~h}$
(ROMP) of strained bicyclic olefins such as norbornene and its derivatives. A rare exception was reported by Porri and coworkers in 1974: an ill-defined system comprising $\left[\mathrm{Ir}(\mathrm{coe})_{2} \mathrm{Cl}_{2}-\mathrm{AgO}_{2} \mathrm{CCF}_{3}\right.$ (2 equiv.) $-\mathrm{HO}_{2} \mathrm{CCF}_{3}$ (14 equiv.) was found to catalyse ROMP of relatively unstrained cycloolefins such as cyclopentene and coe. ${ }^{2,3}$ This same system was also found to simultaneously metathesize and isomerize an acyclic olefin, pent-1-ene, to give $\mathrm{C}_{4}, \mathrm{C}_{5}, \mathrm{C}_{6}$ and higher olefins. ${ }^{3}$ The role of the acid and silver salt was unclear, ${ }^{4}$ and acyclic functionalized olefins were not studied. We are interested in developing late metal catalysts for acyclic functionalized olefin metathesis, ${ }^{5}$ and have been reinvestigating the Porri catalyst system.

We have found that a highly active catalyst for acyclic olefin metathesis/isomerization ${ }^{6}$ can be prepared in situ from the two component system $\left[\mathrm{Ir}(\mathrm{coe})_{2} \mathrm{Cl}_{2}-\mathrm{AgO}_{2} \mathrm{CCF}_{3}\right.$; addition of acid is not necessary. The molar ratio of $\mathrm{AgO}_{2} \mathrm{CCF}_{3}$ : $\left[\mathrm{Ir}(\mathrm{coe})_{2} \mathrm{Cl}\right]_{2}$ must be $\geqslant 4: 1$; a lower ratio (e.g. $2: 1$ ) results in extensive olefin isomerization, but no metathesis activity is observed. Analysis by XRD of the insoluble product formed in the reaction between $\left[\operatorname{Ir}(\text { coe })_{2} \mathrm{Cl}\right]_{2}$ and $\mathrm{AgO}_{2} \mathrm{CCF}_{3}$ (4 equiv.) in toluene after several hours at $25^{\circ} \mathrm{C}$ shows it to be a mixture of $\mathrm{AgCl}$ and metallic $\mathrm{Ag}$ in roughly equal amounts. Thus, the silver salt serves $(i)$ to precipitate silver chloride and (ii) to oxidize $^{7,8}$ the resulting $\operatorname{Ir}^{1}$ trifluoroacetate complex. An active

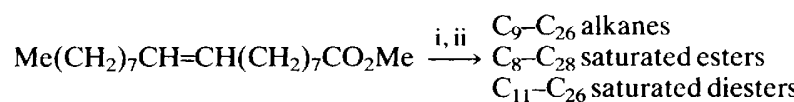

Scheme 2 Reagents and conditions; $\mathrm{i},\left[\operatorname{Ir}(\operatorname{coc})_{2} \mathrm{Cl}\right]_{2}(4 \mathrm{~mol} \%)$, $\mathrm{AgO}_{2} \mathrm{CCF}_{3}(20 \mathrm{~mol} \%)$, toluene, $85^{\circ} \mathrm{C}, 22 \mathrm{~h} ; \mathrm{ii}, \mathrm{H}_{2}(100 \mathrm{psi}), 0.5 \% \mathrm{Pd} /$ C. methanol, $85^{\circ} \mathrm{C}, 18 \mathrm{~h}$

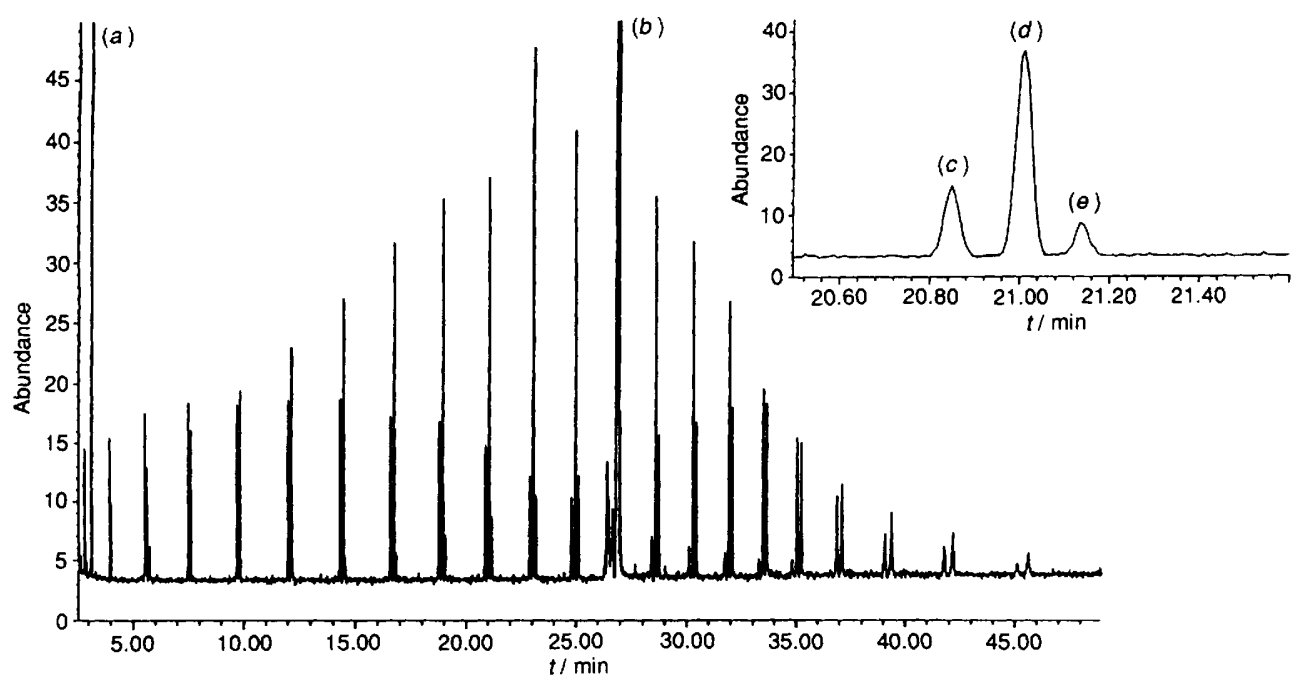

Fig. 2 Gas chromatogram of the product mixture formed in Scheme 2. Peaks corresponding to cyclooctane (a) (derived from hydrogenation of the coe ligand) and methyl octadecanoate $(b)$ (derived from hydrogenation of methyl oleate and its double bond isomers) are off scale. Methyl octadecanoate accounts for $c a$. $50 \%$ of the material present; $\mathrm{C}_{9}-\mathrm{C}_{26}$ alkanes elute between 3 and 35 min; $\mathrm{C}_{8}-\mathrm{C}_{28}$ saturated methyl esters elute between 4 and $45 \mathrm{~min} ; \mathrm{C}_{11}-\mathrm{C}_{26}$ saturated dimethyl esters elute between 14 and $46 \mathrm{~min}$. Inset: expanded plot of the group of peaks with $t_{\mathrm{R}} \approx 21$ min: octadecane, $\mathrm{C}_{18},(c)$, methyl pentadecanoate, $\mathrm{C}_{16},(d)$ and dimethyl dodecandioate, $\mathrm{C}_{14}(e)$. 
catalyst can also be obtained by addition of $\mathrm{AgO}_{2} \mathrm{CCF}_{3}$ ( 2 equiv.) to isolated $\left[\operatorname{Ir}(\mathrm{coe})_{2}\left(\mathrm{O}_{2} \mathrm{CCF}_{3}\right)\right]_{2}{ }_{2}$ in the presence of an acyclic olefin. When $\left[\operatorname{Ir}(\mathrm{coe})_{2}\left(\mathrm{O}_{2} \mathrm{CCF}_{3}\right)\right]_{2}$ is added to an acyclic olefin in the absence of an excess of $\mathrm{AgO}_{2} \mathrm{CCF}_{3}$ a violet solution is formed; the olefin is rapidly isomerized $\$$ but no cross-metathesis of the resulting internal olefins is observed.

Action of the $\left[\operatorname{Ir}(\mathrm{coe})_{2} \mathrm{Cl}_{2}-4 \mathrm{AgO}_{2} \mathrm{CCF}_{3}\right.$ catalyst system on an acyclic olefin is illustrated by the gas chromatogram shown in Fig. 1. Addition of $\left[\mathrm{Ir}(\mathrm{coe})_{2} \mathrm{Cl}_{2}\right.$ to a toluene solution of $\mathrm{AgO}_{2} \mathrm{CCF}_{3}$ (4 equiv.) and octadec-1-ene (25 equiv.) results in a bright orange solution plus a white precipitate $(\mathrm{AgCl})$. When the reaction mixture is allowed to stir for several hours at $25^{\circ} \mathrm{C}$, metallic silver slowly precipitates and metathesis/ isomerization of the starting $\mathrm{C}_{18}$ olefin is observed (Scheme 1). As shown in Fig. 1, new olefins containing 4 to at least 31 carbon atoms can be observed by GC of the reaction mixture. The same result is obtained when $\left[\operatorname{Ir}(\mathrm{coe})_{2^{-}}\right.$$\left.\left(\mathrm{O}_{2} \mathrm{CCF}_{3}\right)\right]_{2}$ is added to a solution of $\mathrm{AgO}_{2} \mathrm{CCF}_{3}$ (2 equiv.) and octadec-1-ene ( 25 equiv.). Metathesis/isomerization of an acyclic functionalized olefin such as methyl oleate can also be effected by $\left[\operatorname{Ir}(\mathrm{coe})_{2} \mathrm{Cl}\right]_{2}-4 \mathrm{AgO}_{2} \mathrm{CCF}_{3}$. In this case the product mixture is complex, consisting of a mixture of isomeric olefins, unsaturated esters and unsaturated diesters over a wide molecular mass range. Hydrogenation to give alkanes and saturated esters and diesters greatly simplifies analysis of the product mixture (Scheme 2), and a gas chromatogram of a hydrogenated mixture is shown in Fig. 2.9 Analysis of this mixture by GCMS indicates the presence of three molecular mass distributions: $\mathrm{C}_{9}$ to $\mathrm{C}_{26}$ linear alkanes, $C_{8}$ to $C_{28}$ linear saturated methyl esters, and $C_{11}$ to $C_{26}$ linear saturated dimethyl esters. Each of the peaks in the gas chromatogram actually consists of two or three closely spaced peaks corresponding to an alkane, an ester, and a diester of nearly identical molecular mass; e.g. the peak with retention time $\left(t_{\mathrm{R}}\right) \mathrm{ca} .21 \mathrm{~min}$ is composed of octadecane, methyl pentadecanoate, and dimethyl dodecandioate [Fig. 2 (inset)].

We have discovered that by allowing $\left[\operatorname{Ir}(\operatorname{coe})_{2} \mathrm{Cl}\right]_{2}$ and an excess of $\mathrm{AgO}_{2} \mathrm{CCF}_{3}$ to react for several hours at room temperature prior to addition of the acyclic olefin, the reaction can become selective for metathesis, instead of metathesis/ isomerization (Scheme 3). When the olefin is methyl oleate, the major products are octadec-9-ene and

$$
\left[\mathrm{Ir}(\mathrm{coe})_{2} \mathrm{Cl}_{2}+6 \mathrm{AgO}_{2} \mathrm{CCF}_{3} \underset{25^{\circ} \mathrm{C}, 22 \mathrm{~h}}{\stackrel{\text { toluene }}{2}} \underset{\text { methyl oleate (10 equiv.) }}{25^{\circ} \mathrm{C}, 8 \mathrm{~h}}\right.
$$

$\mathrm{Me}\left(\mathrm{CH}_{2}\right)_{7} \mathrm{CH}=\mathrm{CH}\left(\mathrm{CH}_{2}\right)_{7} \mathrm{Me}+\mathrm{MeO}_{2} \mathrm{C}\left(\mathrm{CH}_{2}\right)_{7} \mathrm{CH}=\mathrm{CH}\left(\mathrm{CH}_{2}\right)_{7} \mathrm{CO}_{2} \mathrm{Me}$

Scheme 3

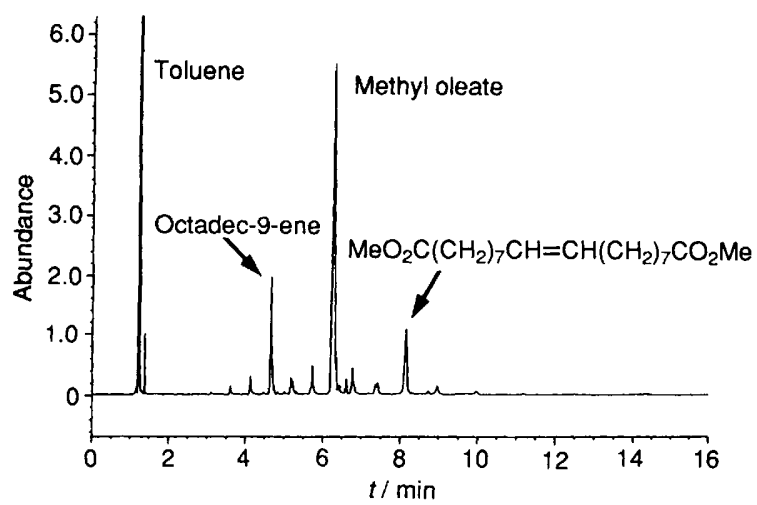

Fig. 3 Gas chromatogram of the product mixture formed in Scheme 3; unlabelled peaks correspond to olefins formed by isomerization/crossmethathesis of the reaction mixture
$\mathrm{MeO}_{2} \mathrm{C}\left(\mathrm{CH}_{2}\right)_{7} \mathrm{CH}=\mathrm{CH}\left(\mathrm{CH}_{2}\right)_{7} \mathrm{CO}_{2} \mathrm{Me}$; i.e. the products of selective methyl oleate metathesis. However, small amounts of products derived from metathesis/isomerization are still observed as shown in Fig. 3.

The iridium catalyst described above is an extremely rare example of a late metal system for acyclic olefin metathesis; our observation of acyclic functionalized olefin metathesis by this system is almost without precedent for a metal from groups $8-10 .{ }^{9}$ Although in the case of methyl oleate metathesis conversions and selectivities are low, it should be emphasized that this is a 'black box' catalyst: the amount of iridium present as active catalyst may in fact be quite small. The development of highly active iridium catalysts for acyclic functionalized olefin metathesis will probably depend on the discovery of routes to iridium carbene complexes in the right oxidation state (we believe $\mathrm{I} \mathrm{r}^{\mathrm{III}}$ ) and with suitable ligands $(e . g$. labile triflouroacetates). This approach has recently met with success in the case of ruthenium catalysts. ${ }^{9 a}$

J. F. thanks Alicia Glatfelter and Beth Fenner for skilled technical assistance. M. B. F. thanks the National Science Foundation for a predoctoral fellowship. R. H. G. thanks the National Science Foundation for support.

Received, 7th February 1994; Com. 4/00747F

\section{Footnotes}

$\dagger$ Contribution no. 8937

$\ddagger$ Contribution no. 6798 .

$\S$ E.g. pent-1-ene in toluene is isomerized to $>95 \%$ pent-2-ene by $\left[\operatorname{Ir}(\mathrm{coc})_{2}\left(\mathrm{O}_{2} \mathrm{CCF}_{3}\right)\right]_{2}(0.5 \mathrm{~mol} \%)$ within $30 \mathrm{~min}$ at $25^{\circ} \mathrm{C}$.

I GC analyses were made using a crosslinked methyl silicone capillary column $(25 \mathrm{~m} \times 0.32 \mathrm{~mm} \times 0.52 \mu \mathrm{m}$ film thickness $)$ and a flame ionization detector.

\section{References}

1 K. J. Ivin, Olefin Metathesis, Academic, New York, 1983, ch. 2.6.

2 L. Porri, R. Rossi, P. Diversi and A. Lucherini, Makrom. Chem., 1974, 175, 3097.

3 L. Porri, P. Diversi, A. Lucherini and R. Rossi, Makrom. Chem., $1975,176,3121$

4 F. Bianchi, M. C. Gallazzi, L. Porri and P. Diversi, J. Organomet. Chem., 1980, 202.99.

5 For recent examples of Mo, W and Re based catalysts for acyclic functionalized olefin metathesis see R. Toreki, G. A. Vaughan, R. R. Schrock and W. E. Davis, J. Am. Chem. Soc., 1993, 115, 127 and references therein.

6 Catalysts that can simultaneously isomerize and metathesize olefins are potentially useful: these reactions carried out sequentially are the basis for the Shell Higher Olefins Process (SHOP); see G. W. Parshall and S. D. Ittel Homogeneous Catalysis, 2nd edn., Wiley, New York, 1992, ch. 4.3.

7 By ${ }^{1} \mathrm{H}$ NMR, the oxidized product appears to be a complex mixture of diamagnetic iridium complexes. The oxidation state of the catalyst is probably I $\mathbf{r}^{\mathrm{III}}$, although $\mathrm{Ir}^{\mathrm{II}}$ cannot be ruled out; oxidation of $\mathrm{Ir}^{\mathrm{I}}$ to $\mathrm{Ir}^{\mathrm{III}}$ by silver triflouroacetate is known: F. A. Cotton and R. Poli, Inorg. Chem., 1987, 26, 590.

8 The oxidation reaction requires several hours at room temp. and likely proceeds via intermediate $\mathrm{Ir}^{\mathrm{l}} \cdot \mathrm{Ag}^{\mathrm{I}}$ complexes; recently, we structurally characterized an $\mathrm{I} \mathrm{r}^{\mathrm{I}} \cdot \mathrm{Ag}^{\mathrm{I}}$ complex formed in the reaction between $\left[\mathrm{Ir}(\operatorname{cod})\left(\mathrm{O}_{2} \mathrm{CCF}_{3}\right)\right]_{2}$ and $\mathrm{AgO}_{2} \mathrm{CCF}_{3}$ (2 equiv.); J. Feldman and $\mathbf{J}$. C. Calabrese, manuscript in preparation.

9 Rare exceptions: (a) S. T. Nguyen and R. H. Grubbs, J. Am. Chem. Soc., 1993, 115, 9858; (b) B. Marciniec and C. Pietraszuk, J. Organomet. Chem., 1993, 447, 163; (c) D. J. Cardin, M. J. Doyle and M. F. Lappert. J. Chem. Soc., Chem. Commun., 1972, 927. 